\title{
EVALUATION OF TRANSCUTANEOUS BILIRUBINOMETRY IN PRETERM INFANTS OF GESTATIONAL AGE 32-34 WEEKS
}

\author{
Lucia Stillova ${ }^{\mathrm{a}}$, Katarina Matasova ${ }^{\mathrm{a}}$, Tatiana Mikitova ${ }^{\mathrm{a}}$, Juraj Stilla ${ }^{\mathrm{b}}$, \\ Hana Kolarovszka ${ }^{a}$, Mirko Zibolen ${ }^{\mathrm{a}}$ \\ a Clinic of Neonatology, Jessenius Faculty of Medicine, Comenius University, Faculty Hospital of Martin, Martin, \\ Slovakia \\ ${ }^{b}$ Clinic of Stomatology and Maxillofacial Surgery, Jessenius Faculty of Medicine, Comenius University, Faculty Hospital \\ of Martin, Martin, Slovakia \\ e-mail: luciastillova@gmail.com
}

Received: August 31, 2007; Accepted: September 28, 2007

Key words: Bilirubin/Minolta JM-103/Neonatal jaundice/Preterm infants

Aims: The aim of this prospective study was to evaluate the accuracy of transcutaneous bilirubinometry using the Minolta Air-Shields JM-103 device in preterm newborns of gestational age 32-34 weeks, and to identify the most appropriate measurement site.

Methods: Transcutaneous bilirubin (TcB) measurements were performed over forehead, sternum and abdomen, if total serum bilirubin (TSB) had to be determined on clinical indication in neonates of selected gestational age. TSB levels were measured in a clinical laboratory using direct spectrophotometry. In order to assess transcutaneous bilirubinometry accuracy, differences between TSB and TcB, their CI95\%, and correlation coefficients (r) between TcB and TSB were evaluated.

Results: The study group consisted of 44 infants, including 6 very low birth weight (VLBW) neonates. The correlations between transcutaneous and laboratory values were found to be significant and close. Minimal differences were observed when measured over sternum. The measurements over forehead had a tendency to underestimate TSB levels.

Conclusions: Noninvasive measurement by Minolta JM-103 demonstrated significant accuracy. The authors recommend measurements over sternum or abdomen in premature infants born within 32-34 gestational weeks as a reliable and accurate neonatal hyperbilirubinemia screening test. Transcutaneous bilirubinometry has the potential to reduce the number of blood samplings, thus reducing neonatal pain and discomfort, parental distress and medical care cost.

\section{INTRODUCTION}

Neonatal jaundice remains an important neonatal issue. It is one of the most common symptoms found in newborn babies, and the condition is mostly benign. The potential toxicity of bilirubin however has to be kept in mind. Although rare, acute bilirubin encephalopathy or kernicterus cases continue to occur, and are associated with significant morbidity and mortality ${ }^{1}$. In order to reduce the risk of developing serious hyperbilirubinemia, phototherapy is the method of choice. It is vital to identify jaundiced infants who are in need of phototherapy as soon as possible ${ }^{2}$. Visual judgement of jaundice is not objective. On the other hand, recent method of choice for establishing the diagnosis of neonatal hyperbilirubinemia is not ideal. Total serum bilirubin (TSB) level assessment in clinical laboratory is an objective method, but the results provided are not real-time. It is expensive, and there is significant interlaboratory and intralaboratory variability. The necessary blood sampling is painful and associated with the possibility of local infection. Transcutaneous measurement of bilirubin concentration is considered to be ideal for neonatal jaundice screening. Transcutaneous readings are immediate, and they can indicate the need for total serum bilirubin testing. Reduction in number of invasive blood tests is associated with reduction in pain and discomfort for newborns and in parental distress and reduction in health costs. A number of factors such as gestational age, birth weight, skin color, phototherapy or degree of jaundice on accuracy of transcutaneous bilirubinometry require further study. There are various transcutaneous bilirubinometry devices. We have been using Minolta Air-Shields Jaundice Meter 103 as a jaundice-screening device for term neonatal population since 2003.

The aim of the study was to evaluate the accuracy of transcutaneous bilirubinometry in a specific population of preterm newborns with a gestational age of 32-34 weeks, and to identify the most appropriate measurement site.

\section{METHODS}

The prospective study was approved by the institutional review board of Jessenius Medical Faculty. Preterm infants of particular gestational age were included in the 


\section{Linear regression}

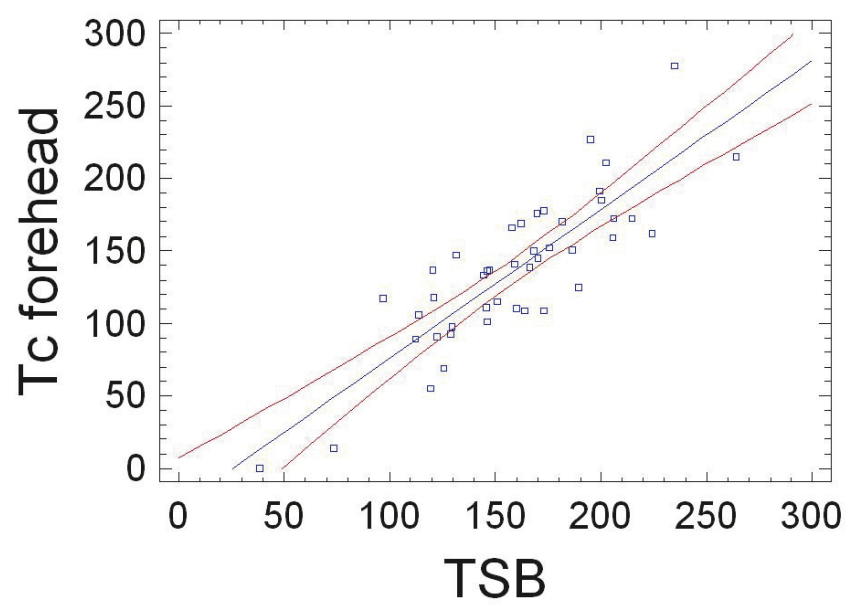

\section{Linear regression}

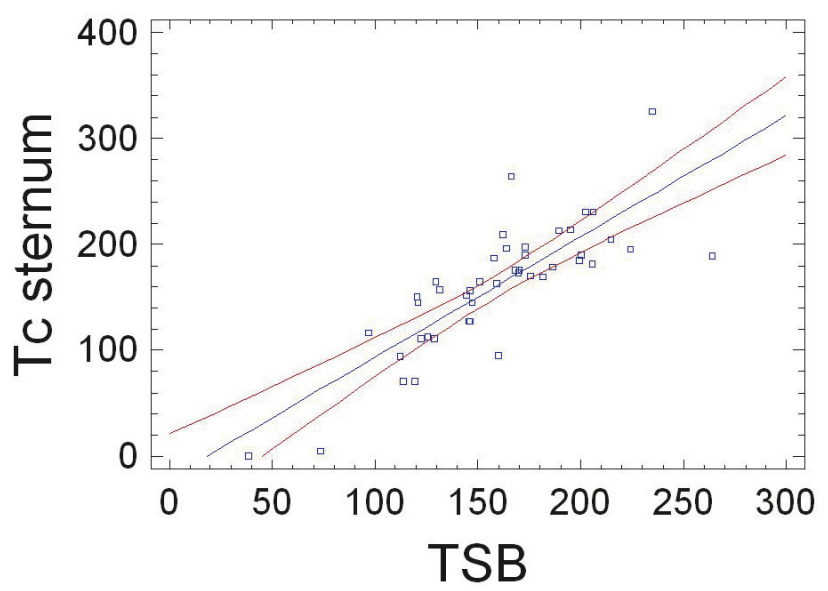

\section{Linear regression}

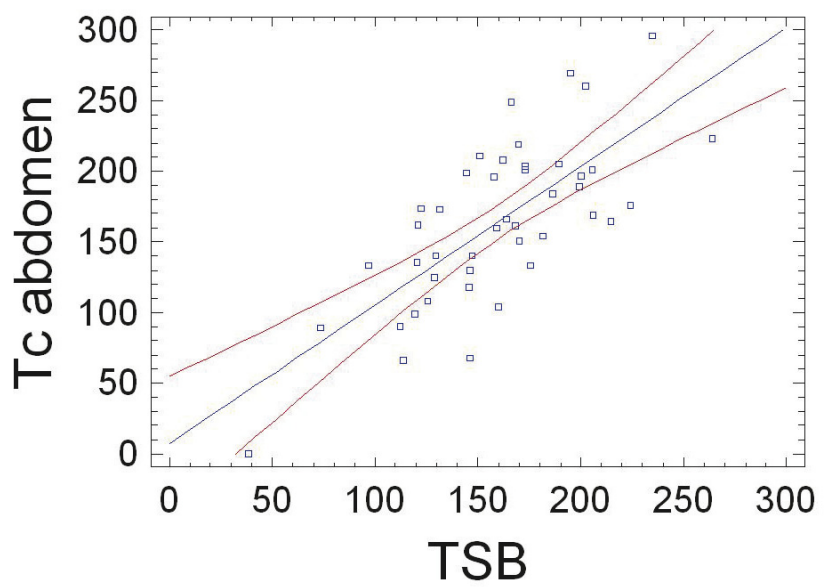

Fig. 1. Linear regression plots of TSB versus JM-103 TcB measurements obtained from different body sites (forehead, sternum, abdomen) of the study group $(n=44)$. study if visual observation of jaundice raised concern for risk of hyperbilirubinemia and TSB determination was necessary within the first two weeks of their life. The criteria for exclusion were phototherapy, exchange transfusion and major congenital malformations.

The Minolta JM-103 probe was placed against the forehead, sternum and abdomen of the infant in a supine position. A computerized average of three consecutive readings over each measurement site was displayed as the transcutaneous bilirubin (TcB) level in $\mu \mathrm{mol} / 1$. Blood samples were drawn from a peripheral vein within 10 minutes of transcutaneous measurement. TSB levels were measured in our hospital's clinical chemistry laboratory using the method of direct spectrophotometry. One transcutaneous measurement and one laboratory measurement were performed in each newborn, in order to acquire only one data set per infant. Pearson linear regression analysis was performed, obtaining correlation coefficients ( $r$ ) between TcB and TSB. $p$ values of less than 0.05 were considered to be statistically significant. In order to assess the accuracy of noninvasive bilirubin concentration measurement, differences $(\Delta)$ between TSB and TcB, and their $95 \%$ confidence intervals (CI95\%) were evaluated.

\section{RESULTS}

A total of 44 jaundiced preterm infants (26 males, 18 females) of Caucasian race, including 6 VLBW neonates (with birth weight less than $1500 \mathrm{~g}$ ), were evaluated. The infants born within 32-34 gestational weeks who required TSB level measurement on clinical indication within the first two weeks of life were included in the study. Newborns receiving phototherapy, post exchange transfusion and those with major congenital malformations were excluded from the study group. Gestational age at birth ranged from 32 to 34 weeks $[\mathrm{x}($ mean $)=33.5$, $\mathrm{SD}=0.7]$, postnatal age from 0 to 13 days $(\mathrm{x}=4.8, \mathrm{SD}$ $=2.7)$, birth weight from 1110 to $2400 \mathrm{~g}(\mathrm{x}=1955, \mathrm{SD}=$ 308.4). TSB ranged from 38.3 to $263.7 \mu \mathrm{mol} / \mathrm{L}$ ( $\mathrm{x}=159.4$, $\mathrm{SD}=42.3$ ).

The correlations between TSB and TcB were found to be significant and close when measured at any of the three sites. The correlation coefficients for TSB versus $\mathrm{TcB}$ measurements over forehead, sternum and abdomen were $0.85,0.81$ and 0.73 , respectively. (Figure 1).

Mean differences $(\Delta)$ between TSB and TcB and their CI95\% for particular measurement sites are shown in Table 1. Transcutaneous measurements over sternum and abdomen show significant differences $(\mathrm{p} \geq 0.05)$. Minimal differences were found when measured over sternum. Measuring over abdomen seems to be also suitable for hyperbilirubinemia screening. The measurements over forehead had a tendency to underestimate serum bilirubin levels significantly $(\mathrm{p}<0.05)$. (Figure 2$)$. 


\section{Preterm newborns}

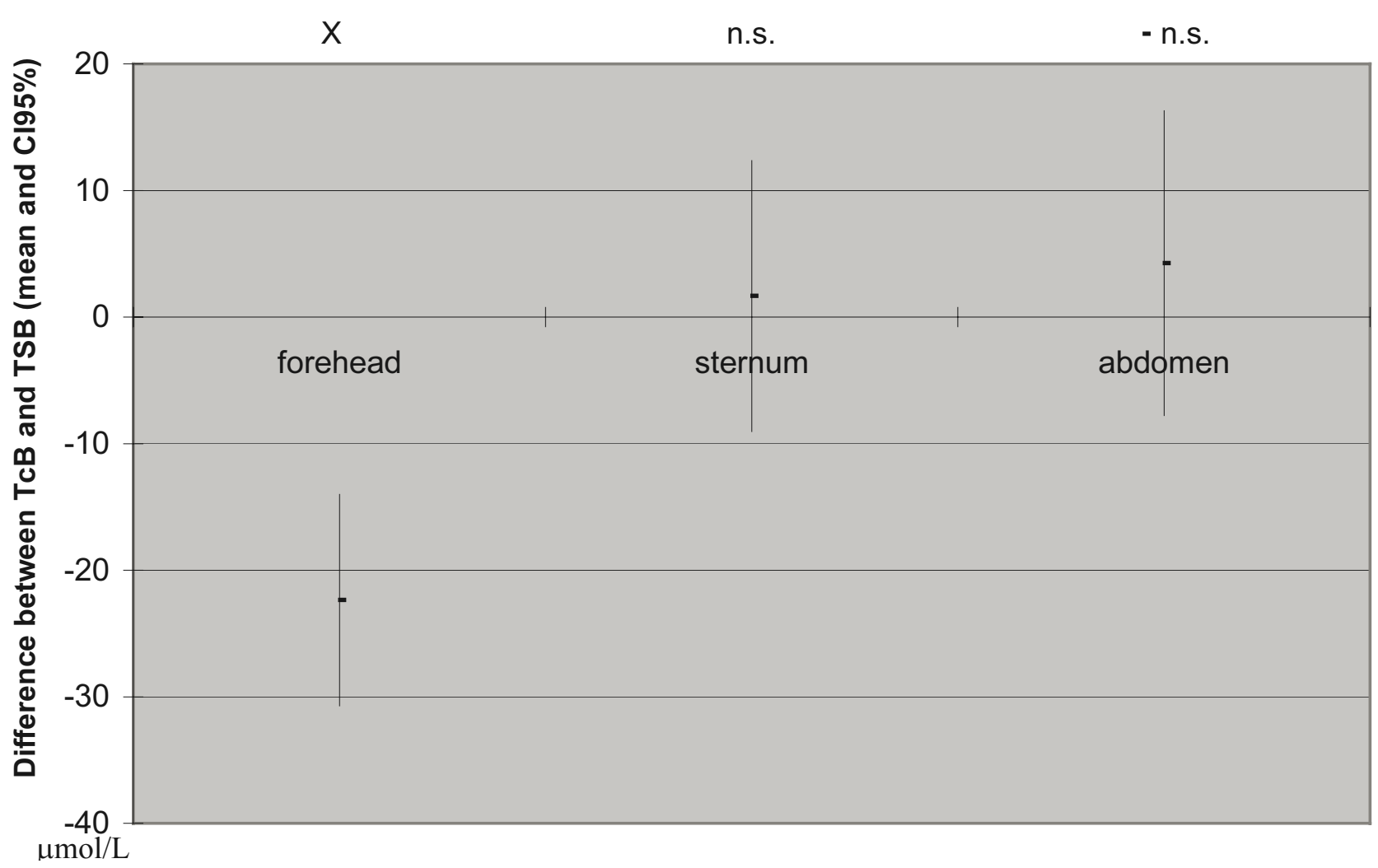

Fig. 2. Mean differences ( $\mu \mathrm{mol} / \mathrm{L})$ between transcutaneous bilirubin $(\mathrm{TcB})$ and total serum bilirubin (TSB) values and their $95 \%$ confidence intervals, according to the site of transcutaneous measurements. Statistical significance is specified (forehead: $p<0.05 \mathrm{X}$; sternum: $\mathrm{p} \geq 0.05$ n.s.; abdomen: $\mathrm{p} \geq 0.05$ n.s.).

\section{DISCUSSION}

The Minolta Jaundice Meter-103 determines the yellowness of the subcutaneous tissue of a newborn infant by measuring the difference between optical densities for light in the blue and green wavelength regions. Since the optical density difference shows a linear correlation with serum bilirubin concentration, it is converted into TSB and indicated digitally ${ }^{3}$. Advantages of the noninvasive measuring technique are real-time results, cost-effectiveness and avoidance of pain and local infection. Minolta JM-103 TcB assessment demonstrates significant accuracy compared to TSB and can be used as a screening test to identify the need for blood sampling for TSB levels in term and near-term newborn infants ${ }^{3-7}$. Ho et al. (2006) reported that combining the use of TcB JM-103 and the 75th centile in Bhutani's nomogram as the cut-off level can identify all cases of significant hyperbilirubinemia in term and near-term newborns ${ }^{8}$. Maisels et al. (2004) reported that in the black population the JM-103 TcB measurements were less accurate than in the other population groups ${ }^{7}$. Although Engle et al. (2005) did not consider JM-103 to be a reliable substitute for laboratory TSB measurement, they suggested that in term and near-term neonates it may facilitate management of hyperbilirubinemia by reducing the number of TSB determinations required ${ }^{9}$.
Use of the Minolta JM-103's two-point method for TcB measurement reduces the influence of neonatal skin maturation level on the results accuracy ${ }^{10}$. However, the use of this particular device in premature infants has not been satisfactorily validated, although hyperbilirubinemia in preterm infants is an important issue. The incidence of hyperbilirubinemia in premature neonates is higher and its course is more serious and prolonged, in comparison with term infants ${ }^{11}$. Yasuda et al. (2003) included 24 preterm infants in their Minolta JM-103 study group, and reported a similar regression line between TcB and TSB to term infants ${ }^{3}$. Namba and Kitajima (2007) measured TcB over forehead in preterm and VLBW Japanese infants. They concluded that the TcB measurements were safe and accurate in these infants. However, they reported a low reliability in patients whose birthweights were lower than $1000 \mathrm{~g}$ or whose gestational ages were shorter than 28 weeks $^{12}$.

The accuracy of transcutaneous bilirubinometry in preterm infants was otherwise studied only using devices such as BiliCheck or the older Minolta JM-102. The conclusions are conflicting. According to Nanjundaswamy et al. (2004) BiliCheck measurements can accurately predict TSB values lower than $188 \mu \mathrm{mol} / 1$ in a multiracial preterm and term neonatal population ${ }^{13}$. In agreement, Willems et al. (2004) reported the BiliCheck as reliable in very preterm infants of gestational age less than 30 weeks ${ }^{14}$. 
Table 1.

\begin{tabular}{|c|c|c|c|}
\hline & Forehead $(\Delta \mathrm{F})$ & Sternum $(\Delta \mathrm{S})$ & Abdomen $(\Delta \mathrm{B})$ \\
\hline$\Delta(\mu \mathrm{mol} / 1)$ & -22.4 & 1.7 & 4.3 \\
\hline $\mathrm{CI} 95 \%(\mu \mathrm{mol} / \mathrm{l})$ & $+/-8.4$ & $+/-10.7$ & $+/-12.0$ \\
\hline $\mathrm{p}$ & $\mathrm{p}<0.05$ & $\mathrm{p} \geq 0.05$ & $\mathrm{p} \geq 0.05$ \\
\hline
\end{tabular}

On the other hand, Eyw et al. (2006) recommended the BiliCheck as a useful screening tool for neonatal jaundice in the neonates with gestation above 32 weeks ${ }^{15}$. Rubaltelli et al. (2001) recommended BiliCheck as a reliable substitute of TSB determination in newborns who are of more than 30 weeks of gestation ${ }^{16}$. Also Knupfer et al. (2001) were given reliable results only in newborns older than 30 weeks of gestation ${ }^{17}$. Jangaard et al. (2006) reported that the Bilicheck instrument was less sensitive in their small sample of preterm infants ${ }^{18}$. According to Mercanti et al. (2007), although the need for phototherapy cannot be determined by BiliCheck measurements in preterm infants, the TcB is reliable when its value is under the limits for phototherapy ${ }^{19}$. Minolta JM-102 was found to be a reliable bilirubin measurement device in VLBW infants, enabling reduction in the need for plasma bilirubin measurements without missing true hyperbilirubinemia ${ }^{20}$.

Among modern measurement methods the Minolta JM-103 device appears to be the most effective noninvasive hyperbilirubinemia screening tool in preterm infants. Moreover, the accuracy of JM-103 in predicting TSB in term and near-term infants was higher compared with BiliCheck at all TSB levels ${ }^{21}$. In a previous study we found that the Minolta JM-103 measurements over forehead tended to underestimate TSB levels in term infants with TSB more than $220 \mu \mathrm{mol} / 1$. Measurements over sternum and abdomen accurately predicted TSB levels ${ }^{4}$. In the current study, we also report similar results in preterm infants. According to the presented results, the measurements over forehead in preterm neonates of the particular gestational age had a tendency to underestimate TSB levels, which is in agreement with the study of Sanpavat et al. (2004) (ref. ${ }^{5}$. In preterm infants phototherapy is indicated at lower TSB values than in term infants. For this reason it is necessary to determine TSB in preterm infants with clinically evident jaundice. If gestational age is $31-32$ weeks, the phototherapy indication criterion is TSB level $200-250 \mu \mathrm{mol} / 1$, and if gestational age is $33-34$ weeks it is $230-280 \mu \mathrm{mol} / 1\left(\right.$ ref. $^{22}$ ). From this point of view, the TSB range presented in our study group is considered sufficient.

In conclusion, noninvasive $\mathrm{TcB}$ measurement by Minolta JM-103 has demonstrated significant accuracy compared to TSB measured by clinical laboratory methods. We recommend Minolta JM-103 measurements over sternum or abdomen in infants born within 32-34 gestational weeks as a reliable and accurate neonatal hyperbilirubinemia screening test. The simple and uncomplicated operating procedure for the Minolta JM-103 assists in the identification of neonates in need of TSB laboratory assessment. Although serum bilirubin measurements are still required when treatment with phototherapy or exchange transfusion is being considered, transcutaneous bilirubinometry has the potential to reduce the number of blood samplings, thus reducing neonatal and parental distress and medical care cost.

\section{LIST OF ABBREVIATIONS}

TSB - total serum bilirubin

TcB - transcutaneous bilirubin

$\Delta$ - difference between TcB and TSB

CI95\% - 95\% confidence intervals

VLBW - very low birth weight

\section{ACKNOWLEDGEMENT}

This work was supported by a grant from Comenius University, Bratislava, Slovakia (Grant Univerzity Komenského č. UK/87/2007).

\section{REFERENCES}

1. Subcommittee on hyperbilirubinemia. Management of hyperbilirubinemia in the newborn infant 35 or more weeks of gestation. Pediatrics 2004; 114(1):297-316.

2. Ip S, Chung M, Kulig J, O’Brien R, Sege R, Glicken S, Maisels MJ, Lau J, Subcommittee in hyperbilirubinemia. An evidence-based review of important issues concerning neonatal hyperbilirubinemia. Pediatrics 2004; 114(1):130-153.

3. Yasuda S, Itoh S, Isobe K, Yonetani M, Nakamura H, Nakamura M, Yamauchi Y, Yamanishi A. New transcutaneous jaundice device with two optical paths. J Perinat Med 2003; 31:81-88.

4. Matašová K, Zibolen M, Čiljak M, Kolarovszká H, Murgaš D, Baška T. Spol'ahlivost' neinvazívneho merania koncentrácie bilirubínu u zdravých novorodencov. Čes.-slov. Pediat. 2005; 60:599-605.

5. Sanpavat $S$, Nuchprayoon I. Noninvasive Transcutaneous Bilirubin as a Screening Test to Identify the Need for Serum Bilirubin Assessment. J Med Assoc Thai 2004; 87:1193-1198.

6. Barko HA, Jackson GL, Engle WD: Evaluation of a point-of-care direct spectrophotometric method for measurement of total serum bilirubin in term and near-term neonates. Journal of Perinatology 2006; 26:100-105.

7. Maisels MJ, Ostrea EM, Touch S, Clune SE, Cepeda E, Kring E, Gracey K, Jackson C, Talbot D, Huang R. Evaluation of a New Transcutaneous Bilirubinometer. Pediatrics 2004; 113:16281635.

8. Ho HT, Ng TK, Tsui KC, Lo YC. Evaluation of a new transcutaneous bilirubinometer in Chinese newborns. Archives of Disease in Childhood - Fetal and Neonatal Edition 2006; 91:F434-F438. 
9. Engle WD, Jackson GL, Stehel EK, Sendelbach DM, Manning MD. Evaluation of a transcutaneous jaundice meter following hospital discharge in term and near-term neonates. J Perinatol. 2005; 25(7):486-90

10. Yamanishi A, Yamauchi Y, Kabe K, Ino M. New transcutaneous bilirubin measurement unit with two optical paths. Acta Neonat Jpn 2001; 37:415.

11. Bystrická A, Bauer F. Iktery u extrémne nezrelých novorodencov. In: Demová K., Bystrická A., Bauer F. Pokroky v neonatológii 1Extrémne nezrelý novorodenec. Vydavatel'stvo NNSP; 2006. p. 45-60.

12. Namba F, Kitajima H. Utility of a new transcutaneous jaundice device with two optical paths in premature infants. Pediatrics International 2007; 49:497-501.

13. Nanjundaswamy S, Petrova A, Mehta R, Bernstein W, Hegyi T. The accuracy of transcutaneous bilirubin measurements in neonates: a correlation study. Biol Neonate 2004; 85:21-25.

14. Willems WA, van den Berg LM, de Wit H, Molendijk A. Transcutaneous bilirubinometry with the Bilicheck in very premature newborns. Journal of Maternal-Fetal and Neonatal Medicine 2004; 16:209-214.

15. Eyw H, Syr L, Cb C, Jwy C. BiliCheck transcutaneous bilirubinometer: a screening tool for neonatal jaundice in the Chinese population. Hong Kong Med J 2006; 12 (2):99-102.
16. Rubaltelli FF, Gourley GR, Loskamp N, Modi N, Roth- Kleiner M, Sender A, Vert P. Transcutaneous bilirubin measurement: a multicenter evaluation of a new device. Pediatrics 2001; 107(6):12641271.

17. Knupfer M, Pulzer F, Braun L, Heilmann A, Robel-Tillig E, Vogtmann C. Transcutaneous bilirubinometry in preterm infants. Acta Paediatr 2001; 90:899-903.

18. Jangaard KA, Curtis H, Goldbloom RB. Estimation of bilirubin using BiliChek, a transcutaneous bilirubin measurement device: Effects of gestational age and use of phototherapy. Paediatr Child Health 2006; 11:79-83.

19. Mercanti I, Michel F, Thomachot L, Loundou DA, Nicaise C, Vialet R, DiMarco JN, Lagier P, Martin C. Transcutaneous bilirubin measurement in preterm infants. Archives de Pédiatrie 2007; 14(7):875-880.

20. Karolyi L, Pohlandt F, Muche R, Franz AR, Mihatsch WA. Transcutaneous bilirubinometry in very low birthweight infants. Acta Paediatrica 2004; 93:941-944.

21. Sanpavat S, Nuchprayoon I. Comparison of two transcutaneous bilirubinometers- Minolta AirShields Jaundice Meter JM103 and Spectrx Bilicheck - in Thai neonates. Southeast Asian J Trop Med Public Health 2005; 36:1533-7

22. Rennie JM, Roberton NRC. Neonatal Jaundice and Liver Disease. In: Rennie JM, Roberton NRC. A Manual of Neonatal Intensive Care. 4. vyd. London: Arnold; 2002. 417-418. 